for some months the results of such charlatanism, before sanctioning by its authority one operation or another, or indeed any operation at all. Magna est veritas, et pravalebit.

\section{ROYAL MEDICAL AND CHIRURGICAL SOCIETY. \\ Tuesday, March 28, 1841.}

Dr. WILLIAMs, President.

READ, OBSERVATIONS ON THE BLOOD DIBCS AND THEIR CONTENTS. BY JOHN QUECKETT, STUDENT OF HUMAN AND COMPARATIVE ANATOMY AT THE ROYAL COLLEGE OF SURGEONS. COMMUNICATED BY DR. PEREIRA.

T'H E author's observations in the paper whose title has first been given, lead him to the following conclusions. That each red particle of human blood is a flattened circular disc, consisting of an outer membrane or envelope, with a gelatiniform fluid in its interior, which, under certain circumstances, is capable of becoming granular, and of escaping from the envelope in the form of small globules; the general number from each disc being about six or seven; and that the discs may present either a biconvex or biconcave surface, the latter form being, by far, the most common. The author has hitherto failed in making out the existence of a central spot or nucleus as usually described. He declines stating at present what he has ascertained the contained granules to be, intending to lay before the Society, at some future period, not only this, but an important part played by them in some of the effects of inflammation.

The author describes at considerable length the appearances presented by the granules, both in the act of escaping from the discs, and afterwards pointing out the confirmation furnished by his observations, of the correctness of the description given by Lewenhoeck, of the appearances presented by the globules of the blood, that distinguished observer having described each disc as composed of six smaller ones.

REA d also, a Case OF Partial softening OF THE RIGHT CORPUS STRIATUM, AND LEFT LOBE OF THE CEREBELLUM, WITH IMPERFECT PARALYSIS OF THE LEPT ARM AND RIGHT LEG.

The patient is described as having suddenly lost all sensation and almost all power of motion in the left arm and right leg; neither the intellect nor any organs of sense having been affected before or being affected after the attack. The only preceding syınptom had been muscular weakness. She appeared to have undergone a fit, which lasted about half an hour, five months before. Between her admission into St. Thomas's Hospital, September 15, 1840, and her death, she regained the complete power of retaining her evacuations, which had been lessened, but not destroyed, by the last attack; and up to the 3rd of November, her other paralytic symptoms had diminished. On that day, 2 fit occurred and was repeated January the 6 th, 13 th, and 23rd. In a few hours after the last fit she died. The pulse had been uniformly slow and feeble; her strength had been supported, and no active treatment adopted.

Serum was found, on examination, under the arachnoid of the brain; otherwise it was healthy, except at two points, in which there was a softened portion of medullary substance, namely, in the right corpus striatum and the left lobe of the cerebellum.

The cause of death in this case, the author presumes to have existed in the softened points, which he considers as not of the nature of apoplectic clots or of ramollissement; and he considers the mode in which the lesion produced death, as different in kind from what is usually observed where organic disease, after long quiescence, becomes the cause of death. He, therefore, presumes this event was attributable to disease distinct from the parts primarily affected.

The author, in conclusion, points out discrepancies between the phenomena of this case, and the general rules laid down in regard to the relation between the affected portions of brain and the paralyzed parts of the body; and expresses his opinion, that these rules rest at present on an imperfect foundation.

\section{WESTMINSTER MEDICAL SOCIETY.}

Saturday, March 20, 1841.

Mr. streeter, President.

STAMMERING.-MR. YEARSLEY READ A PAPER ON STAMMERING, IN WHICH HE DESCRIBED AN OPERATION WHICH HE BELIEVED TO BE PECULIAR TO HIM.

Mr. Yearsley, in most cases, removed the uvula entirely, chiefly with the view of throwing both arches of the palate into one. When the tonsils were so much enlarged as to project beyond the columns of the fauces, the uvula was then partially removed, and also so much of the tonsils as projected : in only one case had anything like severe hæmorrhage taken place, and in this the bleeding. continued for four hours. The operation, however, might not be unattended with danger, when there was a diathesis to hæmorrhage present in the system.

Mr. Dowing believed that three kinds of operation had been recommended and performed for the cure of stammering; the one proposed by $\mathbf{M r}$. Yearsley, that described by Dieffenhach, and that practised by Mr. Bennett Lucas. He (Mr. Dowing) had seen cases operated upon by Mr. Yearsley and Mr. Lucas. In all these cases, as well as in those he had seen operated upon by Mr. Yearsley, the operation at the time certainly appeared successful; but he contended that we had not yet had sufficient time to determine whether the good effect would be permanent. Looking at the invariable success of all the operations, which were so remarkably different in kind, he could not help thinking that much of the effect was dependent on the shock to the nervous system by the operation and the loss of blood consequent upon it. Mr. Lucas's operation consisted in the division of the frænum linguæ, and the removal of a portion of the anterior fibres of the genio-hyo-glossi muscles : Mr. Lucas did not perform his operation indiscriminately on all who applied, as Mr. Yearsley appeared to do, but always thoroughly examined into each case, and investigated, as far as possible, into its history and causes; he only operated in such cases as were likely to be benefited by the proceeding. In the fourteen cases operated upon, the tongue was tied down either by the frænum or the muscles beneath; and in all these cases the operation had been successful. In other cases the success had appeared 